\title{
Praksisopplæring i kroppsøvingslærar- og idrettsutdanningar: 3 utfordringar for framtidig fagutvikling
}

\author{
Øyvind Førland Standal ${ }^{1 \star}$, og Kjersti Mordal Moen ${ }^{2}$ \\ ${ }^{1}$ Seksjon for kroppsøving og pedagogikk, Norges idrettshøgskole, Avdeling for folkehelsefag, \\ Høgskolen $i$ Innlandet; ${ }^{2}$ Avdeling for folkehelsefag, Høgskolen $i$ Innlandet
}

\begin{abstract}
Samandrag
Praksis er ein viktig del av yrkesretta utdanningar. Trass i dette har det vore lite forsking på praksis i kroppsøvingslærarutdanninga og andre idrettsvitskaplege utdanningar. I denne artikkelen oppsummerer vi resultat og funn frå tre ulike forskingsprosjekt som på ulike vis har undersøkt slik praksisopplæring. Metodisk sett har desse undersøkingane vore systematisk litteraturstudie, fokusgruppeintervju og aksjonsforsking. Ei særleg utfordring som undersøkingane vi har vore involvert i peikar på, er samarbeidet mellom undervisarar på høgskulane, praksisrettleiarar (øvingslærarar) og studentar. På bakgrunn av våre funn og ei kunnskapsoppsummering av partnarskapmodellar i lærarutdanninga diskuterer vi til slutt tre utfordringar for praksis i kroppsøvings- og idrettsvitskaplege utdanningar. Desse utfordringane er (i) å sette studenten si læring i sentrum, (ii) hensiktsmessige medium for refleksjon og (iii) teori-praksisdistinksjonar i utdanningane. På bakgrunn av dette får vi fram konsekvensar våre funn kan ha både for utdanning og vidare forsking når det gjeld praksisopplæringa.
\end{abstract}

Nøkkelord: Kroppsøving; idrettsvitskap; praksisopplering; partnarskap

Received: September, 2016; Accepted: March, 2017; Published: September, 2017

\section{Bakgrunn}

Det siste tiåret har ein sett ei auka interesse rundt forsking på utdanninga av kroppsøvingslærarar både i Skandinavia (sjå t.d. antologien redigert av Backman \& Larsson (2013), så vel som internasjonalt. Forsking i norsk samanheng (t.d. Dowling, 2011; Mordal-Moen \& Green, 2014a, 2014b) har, til liks med internasjonale studiar (t.d. Curtner-Smith, 2007; Curtner-Smith \& Sofo, 2004; Maivorsdotter, Lundvall, \& Quennerstedt, 2014), funne at utdanninga gjer lite for å endre studentar sine typisk tradisjonelle haldningar til faget. Desse tradisjonelle haldningane uttrykker ei

^Korrespondanse: Øyvind Førland Standal, Høgskolen i Oslo og Akershus, Postboks 4, St. Olavs plass, 0130 Oslo, Norway. Email: oyvind.standal@hioa.no 
forståing av kroppsøving som sterkt knytt til organisert idrett, både når det gjeld innhald og undervisningsmåtar (Moen, Westlie, Brattli, Bjørke, \& Vaktskjold, 2015).

Larsson (2009) studerte svensk kroppsøvingslærarutdanning og fann at studentane opererte med eit skarpt skilje mellom teori og praksis, der teori dreidde seg om det som står i bøker og praksis handla å utøve aktivitetar. Vidare fann Larsson at studentane verdsette skulepraksisen høgt. Dette er også funne i norske undersøkingar av kroppsøvingslærarutdanninga. Dowling (2011) fann at studentane verdsette praksis som den delen av utdanninga der dei lærte kva det vil seie å vere lærar. Samstundes fann Dowling at studentane i praksis ikkje blei utfordra, fordi det var dei praktiske sidene ved undervisning som blei vektlagt i skulepraksisen. Dette - saman med andre forhold i utdanninga - gjorde at Dowling konkluderte med at studentane ikkje baserte sine vurderingar av god undervisningspraksis på teoretiske idear om kva som konstituerer "god" praksis. Liknande funn er rapportert i Moen (2011) si doktorgradsavhandling om kroppsøvingslærarutdanning. For studentane i hennar avhandling dreide det å lære å undervise i kroppsøving seg om å instruere $\mathrm{i}$ typisk idrettslege ferdigheiter. Altså ein reproduksjon av studentane sine førforståingar av kroppsøving som eit idrettsdominert fag. Også Moen fann at studentane var meir fornøgd med skulepraksisen enn med dei andre delane av utdanninga.

Sjølv om praksisdelen av utdanninga er eit element i den forskinga som har undersøkt kroppsøvingslærarutdanninga som heilskap, er systematiske undersøkingar av sjølve praksisopplæringa i kroppsøvingslærarutdanninga i Norge ei mangelvare. Det same gjeld andre idrettsvitskaplege utdanningar som har praksisopplæring. Sidan 2011 har vi difor vore engasjerte $\mathrm{i}$ forskingsprosjekt som har undersøkt sider rundt praksis i kroppsøvings- og idrettsutdanningar. Hensikta med denne artikkelen er å samanstille og oppsummere funna vi har gjort. På bakgrunn av dette vil vi drøfte konsekvensar våre funn kan ha både for utdanning og vidare forsking.

\section{Oppsummering av vår forsking}

I dette avsnittet vil vi kort gjere greie for dei viktigaste funna frå vår forsking. Denne artikkelen tar utgangspunkt i 3 delprosjekt som alle har som felles hensikt å undersøke studentars læring i og gjennom praksis. Det er viktig å peike på at ordet praksis kan ha fleire tydingar. I vid forstand kan praksis rett og slett vise til ei form for menneskeleg verksemd, medan det i ei meir bestemt meining kan vise til yrkesverksemd, som t.d. advokatpraksis (Molander \& Terum, 2006). I vår samanheng forstår vi praksis som den delen av ei høgare utdanning der studentane er utplassert i yrkesfeltet. Denne praksisopplaringa skal være rettleia, vurdert og variert, og er eit samarbeid mellom universitetet/høgskolen, praksisstaden og studenten.

\section{Kontekstualisering}

Vi tar i denne artikkelen altså utgangspunkt i funn frå tre delprosjekt om praksisopplæring. Dei tre delprosjekta er skissert i tabellen under. 
Tabell 1. oversikt over delprosjekt og forskingsartiklar

\begin{tabular}{|c|c|c|c|}
\hline & Tittel & Metode & Publikasjon \\
\hline 1 & $\begin{array}{l}\text { Reflektert praksis i kroppsøving } \\
\text { og kroppsøvingslærarutdanninga }\end{array}$ & $\begin{array}{l}\text { Systematisk } \\
\text { litteraturgjennomgang }\end{array}$ & $\begin{array}{l}\text { Standal \& Moe (2011). } \\
\text { Publisert i Quest }\end{array}$ \\
\hline 2 & $\begin{array}{l}\text { Praksisopplæringa i } \\
\text { kroppsøvingslærarutdanningane }\end{array}$ & $\begin{array}{l}\text { Fokusgruppeintervju } \\
\text { med høvesvis studentar, } \\
\text { høgskolelærarar og } \\
\text { øvingslærarar }\end{array}$ & $\begin{array}{l}\text { Moen \& Standal (2013). } \\
\text { Publisert i Nordic Studies of Education } \\
\text { Standal, Moen \& Moe (2013). } \\
\text { Publisert i European Physical Education Review } \\
\text { Moen \& Standal (2016). } \\
\text { Publisert i Sage Open }\end{array}$ \\
\hline 3 & $\begin{array}{l}\text { Utvikling av praksisopplæring } \\
\text { i FAF-studiet }\end{array}$ & $\begin{array}{l}\text { Aksjonsforsking } \\
\text { Teoretisk analyse }\end{array}$ & $\begin{array}{l}\text { Standal \& Rugseth (2014). } \\
\text { Publisert i Adapted Physical Activity Quarterly } \\
\text { Standal \& Rugseth (2016). } \\
\text { Publisert i Quest }\end{array}$ \\
\hline
\end{tabular}

Det som integrerer desse delprosjekta er at dei har undersøkt studentars læring i og gjennom praksis. Delprosjekta har resultert i 6 artiklar som er publisert i anerkjende, fagfellevurdert tidsskrift. I dei neste avsnitt går vi gjennom dei vesentlegast funna i artiklane. Her viser vi til både dei metodiske innfallsvinklane vi har brukt og til teoretiske omgrep som har vore nyttige i analysane våre. På bakgrunn av at vi her ikkje presenterer nye empiriske analyser og at den vitskaplege kvaliteten av delstudiane er vurdert gjennom fagfellevurdering vel vi difor å ikkje gå i djupna på dei metodiske tilnærmingane vi har brukt. Vi vil likevel gjere kort greie for dei viktigaste teoretiske perspektiva vi har brukt.

Når vi i denne artikkelen bruker omgrepet kroppsøvingslærarutdanning, så er dette ei samlenemning for 3 ulike utdanningar. Det er tre vegar til å bli kroppsøvingslærar i det norske utdanningssystemet: ved å (i) studere kroppsøving som ein del av grunnskulelærarutdanninga, (ii) ta ei faglærarutdanning i kroppsøving og idrettsfag og (iii) ved å ta praktisk-pedagogisk utdanning (PPU) på toppen av ein bachelor- og/eller mastergrad innanfor det idrettsvitskaplege feltet. I eit delprosjekt (nr. 2, fokusgruppestudien) har vi inkludert deltakarar frå alle tre utdanningsvegane.

I delprosjekt 3 var hensikta å forstå og forbetre studentars læringsutbyte av praksisopplæringa i påbyggingsstudiet Fysisk aktivitet og funksjonshemming (FAFstudiet). Dette utdanningsprogrammet tar opp studentar med ein bachelorgrad i idrettsvitskap eller ein bachelor i helse- og sosialfag (t.d. fysio-, ergoterapi eller vernepleie), men med basisår i idrettsvitskap. Sjølv om praksiskonteksten for dette studiet ikkje er skulen, slik som i kroppsøvingslærarutdanninga, så har den likevel det til felles med kroppsøvingslærarutdanninga at studentane skal lære å leie andre personar sine læringsprosessar i bevegelsesaktivitetar.

Prosjekta vi presenterer her er ikkje eksternt finansiert, men derimot driven fram av vår eiga interesse for å forstå og utvikle dei utdanningsprogramma vi sjølve har vore involvert i. Denne artikkelen er såleis å forstå som ei oppsummering av fleire års arbeid med å undersøkje studentar si læring i og gjennom praksis. 


\section{Reflektert praksis i kroppsøving og kroppsøvingslærarutdanninga}

Refleksjon og reflektert praksis er nøkkelomgrep i profesjonsutdanningar, slik som i kroppsøvingslærarutdanninga. I ein Britisk rapport om forskinga si rolle i lærarutdanninga blir det hevda at «yrkesutøvinga stiller følgjande krav til lærarar: praktisk forståing og handlingskompetanse (know-how); ei god konseptuell forståing av utdanning og undervisning; og evna til å forstå, tolke og danne kritiske vurderingar av empirisk forsking og relevansen den har for partikulære situasjonar» (Winch, Oancea, \& Orchard, 2015, s. 211. Vår omsetting). I eit slikt bilete blir refleksjon eit tilknytingspunkt mellom praktisk utøving på den eine sida og teori og empirisk forsking på den andre sida.

Når det gjeld kunnskapsstatusen på reflektert praksis i kroppsøving og kroppsøvingslærarutdanning har det blitt gjennomført ei systematisk litteraturstudie (Standal \& Moe, 2013). Det var 33 artiklar som blei inkludert i undersøkinga, og desse blei analysert og diskutert ved hjelp av Wackerhausen (2008) sin refleksjonsanatomi. Wackerhausen sitt arbeid har vore eit fruktbart analyseverktøy både i denne og andre delstudier. Kort forklart hevdar Wackerhausen at på tvers av dei ulike forståingane av refleksjon og reflektert praksis finst det ein felles struktur, ein anatomi. For det første seier Wackerhausen at refleksjon er ein form for systematisk og kritisk tenking. Refleksjonen har alltid eit objekt, noko ein tenker på. Vidare meiner Wackerhausen at når ei tenker på noko, så tenker ein alltid med noko (t.d. teoriar og omgrep), utifrå noko (ei kunnskapsinteresse eller eit sett av verdiar og haldningar) og innanfor noko (dvs. ein kontekst, slik som utdanning eller profesjonelt arbeid i skulen). Desse fire dimensjonane har vore nyttige for å analysere og forstå refleksjon i våre prosjekt.

I analysane av artiklane vi inkluderte i litteraturstudien (Standal \& Moe, 2013) var det tre tema som blei diskutert. For det første, tidlegare forsking har funne at studentane utviklar sine evner til refleksjon, men at dei ikkje blir kritisk-refleksive, slik som mange av forfattarane av artiklane såg ut til å ønskje at dei skulle bli. Til dette vil vi kort nemne at omgrepet kritisk refleksjon ser ut til å ha blitt kapra av pedagogar som høyrer til den kritisk-pedagogiske tradisjonen, slik at kritisk tenking blir forstått til berre å gjelde i dei tilfella der kunnskapsinteressa - det ein tenkjer utifrå - handlar om å avsløre makt og undertrykking i den hensikt å oppnå sosial rettvise. Kritisk tenking forstått slik bør vere ein del av kroppsøvingslærarutdanninga. Likevel går det an å forstå kritisk tenking i eit meir pragmatisk perspektiv som kritisk refleksjon over kvaliteten på eigne og andre sine oppfatningar og slutningar (sjå t.d. Teige, 2016). Om ein legg eit slikt perspektiv til grunn kan ein, som vi kjem tilbake til seinare, komme til andre konklusjonar når det gjeld kor vidt studentane utviklar evne til kritisk refleksjon gjennom utdanninga.

For det andre såg vi at lærarar ønskjer seg eit fellesskap på arbeidsplassen der dei kan reflektere over utfordringar dei møter i arbeidet sitt. I dei undersøkingane som er gjort om kroppsøvingslærarar er det eit gjennomgåande funn at det er eit sug etter å drøfte pedagogiske spørsmål med andre lærarar, men at det i liten grad finst rom og tid for å gjere dette. Det tredje punktet som kom fram i denne undersøking er at 
media for refleksjon var eit viktig tema i litteraturen: Skriving er det vanlegaste mediet å bruke både for å utvikle og vurdere refleksjon hos studentar. Samstundes er det også den vanlegaste måten å forske på studentar sine evne til refleksjon. I diskusjonane våre i denne artikkelen peikar vi på at det ser ut til å vere tatt for gitt at skriving er den beste og mest valide måten å utvikle og undersøke studentar sine refleksjonar. Dette kan ein, som vi vil komme tilbake til, stille nokre spørsmål rundt.

\section{Praksis i kroppsøvingslærarutdanninga}

I delprosjekt 2 har vi analysert fokusgruppeintervju med studentar, høgskule- og øvingslærarar på 3 ulike institusjonar som tilbyr kroppsøvingslærarutdanning. Her har vi har publisert to artiklar på studentmaterialet. I den første artikkelen har vi sett på organiseringa av praksisen, slik den ser ut frå studentane sin ståstad (Moen \& Standal, 2014). Samla sett kan det sjå ut som at organiseringa er lite uniform og prega av tilfeldigheiter. Dette gjeld både mellom høgskulane, men det ser og ut til å gjelde innanfor den enkelte institusjonen. No skal det seiast at dette er slik vi forstår det studentane fortel oss. Ei sak som har vore ganske slåande i dette prosjektet er korleis studentar, høgskule- og øvingslærarar forstår praksisen og det dei gjere i samband med praksisen på forskjellige måtar. Å ha ei felles forståing av det dei held på med i lag ser derimot ut til å vere vanskeleg å få til, noko vi vil komme tilbake til seinare.

Vidare ser vi i denne artikkelen på studenten som ein observerande lærling. Dette er eit omgrep som vanlegvis er brukt for å omtale den profesjonelle sosialisering som finn stad gjennom praksisopplæringa. Referansane går her til Lortie (1975). Det er klart frå vår lesing av litteraturen at 'observerande lærling' har ein negativ klang i form av at det skildrar ein sosialiseringsprosess der studentane ukritisk overtar den praksisen dei blir utsett for. I vårt materiale finn vi at studentane sjølve omtalar seg som lærlingar og at dei oppfattar observasjon som ei viktig kjelde til læring. Men i motsetnad til ein del tidlegare forsking som framstiller det slik at studentane sluker rått det dei blir presentert i praksis og dermed berre blir sosialisert inn i ein kritikkverdig praksis, så nyanserer vår forsking dette biletet. I begge artiklane våre finn vi at studentane faktisk er i stand til å tenkje kritisk både på øvingslærarane si undervisning og rettleiing, og deira eiga og medstudentar si undervisning i praksisen. Det vil seie at vi meiner å sjå at studentane kan tenkje kritisk, men at dei tenkjer med andre kunnskapsressursar og interesser enn det som skal til for å vere kritisk tenking i følgje kritiske pedagogar.

I den andre artikkelen frå studentmaterialet brukte vi Harald Grimen (2008) sine tankar om praktiske syntesar for å forstå korleis studentane handterte teoripraksisgapet i utdanninga (Standal, Moen \& Moe, 2014). Grimen (2008) peikar på at forholdet mellom teori og praksis er komplekst og mangefasettert. Vidare viser Grimen til at kunnskapsbasen til ein profesjon som regel er konstituert av kunnskap frå ulike vitskaplege disiplinar. Til dømes møter studentar i kroppsøvingslærarutdanning så vidt ulike disiplinar som fysiologi, sosiologi og pedagogikk. Spørsmålet blir då kva som skapar samanheng i kunnskapsbasen. Grimen meiner at det som driv fram samanheng er kor vidt ulike former for kunnskap kan danne meiningsfulle element i ein profesjonell praksis. Det som skapar denne samanheng er praktiske syntesar. Med andre ord vil det i følgje Grimen vere slik at krava studentar erfarer i praksisopplæringa 
kan bidra til å skape samanheng i kunnskapsbasen deira. Dette er likevel ikkje noko som skjer automatisk, og studentane kan også erfare at kunnskapsbasen er fragmentert og usamanhengande.

Det vi fann i denne artikkelen er at studentane forstår teori på ulike måtar: det å forklare korleis idrettslege teknikkar skal utførast blir sett på som teori, pedagogikk blir sett på som ein meir abstrakt form for teori, medan det studentane framhevar som nyttig teori er fagdidaktikken. Vi fann også at studentane opplever at høgskulelærarane er fråverande i praksis: lærarane kjem på besøk, men for studentane er hensikta med besøket uklart. I tillegg opplever studentane at deira erfaringar frå praksis ikkje blir gjort relevante i undervisninga på høgskulane. Unnataket er praksisoppsummering og skriving av ulike typar refleksjonsnotat, men desse tiltaka ser ut til å bli oppfatta som ganske uforpliktande pliktløp. Altså, noko dei må skrive og levere inn, men som ikkje blir fulgt opp. Eit viktig funn i denne artikkelen er at meir kan gjerast for å støtte studentane i å skape det Grimen (2008) kallar praktiske syntesar.

I ein tredje artikkel frå dette prosjektet har vi analysert høgskule- og øvingslærarmaterialet saman (Moen \& Standal, 2016). Rammeplanane for kroppsøvingslærarutdanninga slår fast at høgskule- og øvingslærarane skal opptre i eit gjensidig partnarskap og samarbeide om studentane si læring. Difor har vi undersøkt om og korleis dei to gruppene ser på seg sjølv og kvarandre som deltakarar i eit gjensidig partnarskap. I analysane har vi komme fram til to tema, «berre på besøk» og «samarbeid eller polarisering?» Praksisbesøk er eit omgrep som blir brukt i alle institusjonane, og som i vår erfaring er vanleg å bruke i sektoren. På ei side kan ein sjå på det som berre eit uskuldig, kvardagsleg omgrep. Samstundes er det ganske klart for oss at besøk-omgrepet også peikar på at høgskulelærarane både kjenner seg, og oppfører seg, som gjestar når dei er ute i praksisskulane. Dei er på bortebane og trør med varsemd for å ikkje støyte vertskapet.

Vi diskuterer også korleis partnarskapet er kjenneteikna både av samarbeid og av polarisering i korleis dei to gruppene oppfattar sine respektive roller og bidrag. Som vist $\mathrm{i}$ gjennomgangen av tidlegare forsking er skilje mellom teori og praksis ein tankefigur som ser ut til å stå sterkt. Eit interessant funn for oss er difor at forståinga av kva som har forrang; teori eller praksis, går på kryss og tvers av dei to gruppene. Det er strengt tatt ikkje ei polarisering mellom høgskule- og øvingslærarar, men heller mellom akademisering og vektlegging av teori på den eine sida og den praktiske utøvinga av undervisninga i kroppsøvingsfaget på den andre sida. Det vi ser er at skilje går på korleis individuelle medlemmer i gruppene posisjonerer seg med tanke på forholdet mellom kunnskap for praksis og kunnskap $i$ praksis (Hegender, 2010). Denne polarisering vil vi komme tilbake til.

\section{Utvikling av praksisdelen av FAF-studiet}

Det siste delprosjektet er eit aksjonsforskingsprosjekt som hadde til hensikt å undersøkje korleis studentane lærer i praksis og korleis vi som er ansvarlege for utdanninga kan forbetre praksislæringa. Her har vi (Standal \& Rugseth, 2014) brukt Wackerhausen (2008) sitt rammeverk til å analysere studentane sine refleksjonsnotat og eit gruppeintervju med studentane rundt deira erfaringar frå praksis i ulike 
rehabiliteringsinstitusjonar. Feltnotat og forskarrefleksjonar er også med som material i studien. I tillegg til artikkelen frå sjølve aksjonsforskingsprosjektet er det i dette prosjektet også ein teoretisk artikkel som gjere meir utførleg greie for det pedagogiskfilosofiske grunnlaget vi tuftar praksisopplæring i FAF-studiet på (Standal \& Rugseth, 2016).

Det vi fann spesielt interessant i det empiriske materialet er paradokset mellom det å reflektere utifrå og over visse verdiar. Studentane har klare kunnskapsinteresser om å spreie aktivitetsglede og meistring til personane dei møter i praksis, men vi erfarte det som utfordrande å få studentane til å reflektere over desse verdiane. Sagt på ein annan måte: dei reflekterer heilt uproblematisk utifrå verdiar omkring det å vere fysisk aktiv, men når dei blir utfordra til å reflektere over desse verdiane som dei sjølv har, uttrykker dei at refleksjonane blir 'subjektive' og 'navlebeskuande'. Erfaringa frå dette aksjonsforskingsprosjektet er at det ser ut til å krevje eit større pedagogisk arbeid for at studentane skal vere villige til å inkludere seg sjølv og sine eigne normer og verdiar i refleksjonane rundt praksiserfaringar.

Samla sett viser resultata våre at utdanningane vi har undersøkt strevar med forholdet mellom teori og praksis. Ei slik fragmentering er ikkje særleg overraskande. $\mathrm{Ei}$ anna form for fragmentering vi meiner å sjå, ligg i forholda mellom studentar, høgskulelærarar og praksisrettleiarar. Det ser ut til at det er vanskeleg for desse tre gruppene å "snakke det same språket” og å “dra i same retning”. Sett i relasjon til praksisopplaring vil det å dra i same retning bety å sette studentane si læring i sentrum. Likevel må vi understreke at det blir gjort mange tiltak for å bøte på utfordringar rundt organisering og i læring i praksis. Med andre ord kan vi seie at manglande eller svakt samarbeid/partnarskap er eit anerkjent problem i utdanningane. Eit av tiltaka som blir gjort er å sørge for studentane sine refleksjonar om praksis. Ei utfordring rundt refleksjon er ikkje berre innhaldet i refleksjonane, men også konteksten. Med andre kva for medium er det refleksjonen skjer innanfor, for å bruke Wackerhausen (2008) sin terminologi. På bakgrunn av dette vil vi i det følgjande drøfte tre utfordringar for organiseringa av praksisopplæringa: (i) studentane si læring i sentrum, (ii) medium for refleksjon og (iii) teori-praksis-distinksjonen.

\section{Mellomspel: partnarskap i lærarutdanninga}

Utfordringane vi har identifisert på bakgrunn av dei tre delprosjekta våre er ikkje unike for dei utdanningane vi har studert. Sett på spissen har kritikken mot lærarutdanningane (dvs. grunn- eller allmennlærarutdanningane) - og praksisopplæringa der - vore at det er eit gap mellom teori og praksis, «manglande praksisrelevans, manglande indre samanheng, manglande samarbeid mellom fag og manglande relasjonar til praksisfeltet» (Haug, 2013, s. 54). Haug peikar på at desse vurderingane har vore meir ideologisk enn empirisk fundert, og at profesjonsutdanningar i ei viss grad nødvendigvis vil vere fragmentert fordi dei byggjer på ulike kunnskapsformer. På den eine sida er det difor klart at lærarutdanningar i ei viss mon vil vere fragmenterte fordi

dei skal inkorporere ulike kunnskapsformer. Likevel er det ein klar tendens til å jobbe for betre integrasjon i utdanningane (Lund, Jakhelln, \& Rindal, 2015). Integrasjon 
handlar då ikkje om ei «total sammensmeltning av komponenter som utgjør en slags enhetlig legering» (s. 32). Derimot viser integrasjon i lærarutdanning til både «enkeltdeler som bygger opp om hverandre og til sammen gir mer mening enn delene hver for seg i samsvar med en overordnet visjon. . og som opplevd sammenheng av disse integrerte delene som noe begripelig, håndterbart og meningsfullt over tid» (s. 34).

Ein mogeleg måte å skape samanheng er gjennom partnarskap, noko som vil seie meir formaliserte og strukturerte samarbeid mellom lærarutdanningsinstitusjonar og praksisskular. Lillejord \& Børte (2014) har gjort ein systematisk litteraturgjennomgang av forsking om partnerskapmodellar i lærarutdanning. Dei oppsummerte forskinga i 3 kategoriar. Den første handla om relasjonar og samarbeid i partnarskapet. Sentralt her er omgrepet eit tredje rom som skildrar samhandling mellom deltakarane $\mathrm{i}$ partnarskapet og mogelegheitene for meir symmetriske samarbeidsrelasjonar mellom lærarutdannarar og praksisrettleiarar. Den andre kategorien var organisering og leiing av partnarskapet. Her blir det avdekka ulike spenningar mellom deltakarane i samarbeidet. Til slutt peikar Lillejord og Børte på utfordingar ved, og føresetnadar for, vellukka partnarskap der det særleg blir lagt vekt på koordinering og kva for oppgåver aktørane har og tar i samarbeidet. På bakgrunn av undersøkinga konkluderer Lillejord og Børte blant anna med at "de fleste forskerne ser ut til å ta for gitt at den viktigste lærende enheten i lærerutdanningen er triaden mentor-student-veileder", men at denne antakinga ikkje er problematisert, noko som fører til at "spørsmålet om hvordan studentenes praksisopplæring skal struktureres og gjennomføres slik at den støtter studentenes profesjonslæring er dermed fortsatt uavklart i forskningen” (s. 20).

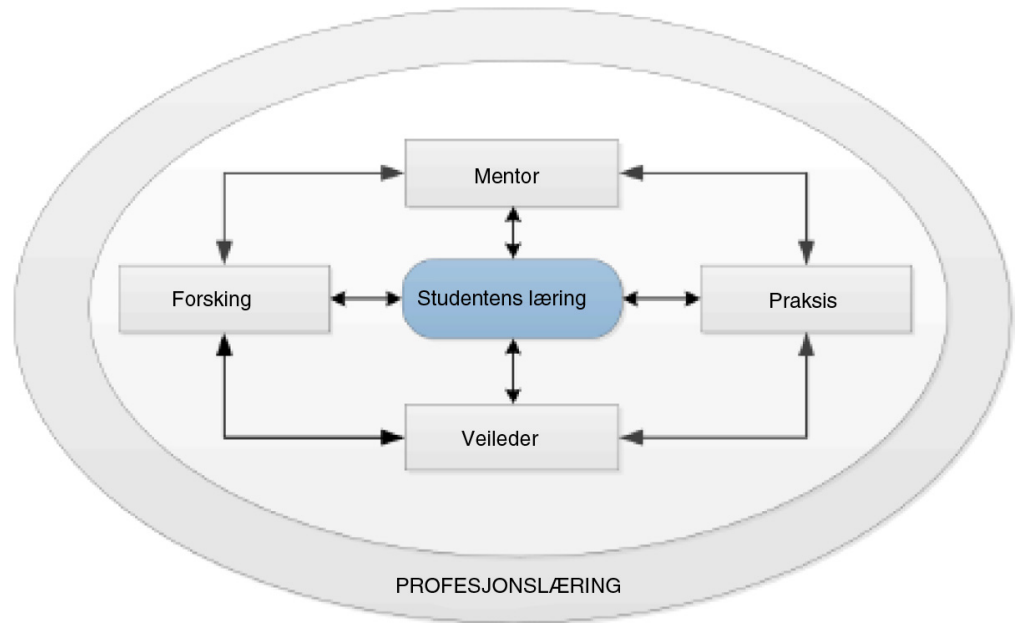

Figur 1. Modell for partnarskap i lærarutdanninga frå Lillejord \& Børte (2014, s. 22).

Ved å bygge vidare på ideen om det tredje rommet og å kritiserer triade-modellen for praksisopplæringa foreslår Lillejord og Børte ein ny modell for samarbeid i partnarskap: 
Der triademodellen bygger på at det skal vere mogeleg å ha symmetriske relasjonar mellom partane i triaden, legg denne modellen opp til å anerkjenne og jobbe utifrå at det er både formelle og uformelle asymmetriske relasjonar mellom partane. Vidare set denne modellen studenten si læring i sentrum, i staden for på ein av aksane som i triademodellen. Dei doble pilene i modellen viser til at både mentor ('øvingslærar') og veileder ('høgskolelærar') er gjensidig ansvarlege 'både for å forstå praksisfeltets utfordringer og være oppdatert om forsking” (s. 22). Dette viser til ein dobbel bevegelse der lærarutdanninga både skal vere FoU-basert og praksisrelevant. Samarbeidet i partnarskapet kan difor potensielt sett gjere forskingsaktiviteten ved lærarutdanninga meir profesjonsrelevant samstundes som yrkesutøvinga blir meir kunnskapsbasert.

\section{Diskusjon}

I det følgjande vil vi drøfte utfordringar på 3 område som er relevante for praksisopplæring i kroppsøvings- og idrettsutdanning: teori/praksis-distinksjonen, medium for refleksjon og studenten si læring i sentrum. Ved å peike på desse utfordringane og sjå dei i lys av Lillejord og Børte si kunnskapsoppsummering, håper vi å bidra til at praksisopplæringa kan bli drøfta på ein kunnskapsbasert måte innanfor dei partnarskapane som skal sørge for praksisopplæring.

\section{Utfordring 1: Student si læring i sentrum}

Å sette studentane si læring i sentrum høyres knapt nok ut som ei utfordring. Snarare vil mange truleg oppfatte det som sjølvsagt: kva elles skal vere i sentrum for skulepraksisen? Likevel viser funna frå våre prosjekt og kunnskapsoppsummeringa til Lillejord og Børte at det ikkje er er så enkelt. Vi har, til liks med anna forsking på kroppsøvingslærarutdanning, funne at det er ulike synspunkt blant studentar, høgskulelærarar og øvingslærar når det gjeld kva som er viktig at studentane lærer gjennom praksisdelen av utdanninga. I Moen \& Standal (2016) ramma vi dette inn som eit maktforhold som er relatert til kven som har definisjonsmakta over $k v a$ studenten skal lære. I same retning peikar Lillejord og Børte (2014, s. 20) på at triaden høgskolelærar - student - øvingslærar oftast blir sett på som ei einig med symmetriske forhold, noko Lillejord og Børte meiner er feil. Som vi også har funne i våre undersøkingar er det i større grad forhold som er asymmetriske. På bakgrunn av dette føreslår Lillejord og Børte ein alternativ modell som set students læring i sentrum (sjå over).

Dette vil seie at det ikkje er så mykje eit spørsmål om det er studentane si læring som står i sentrum, men at det er innhaldet (kunnskapsobjektet) i denne læringa som er utfordrande. Utfordringa som blir peika på av Lillejord og Børte, og som våre undersøkingar viser, er at så lenge det er ulike synspunkt på kva som er det viktigaste kunnskapsobjektet, opplever studentane at dei får "motstridende beskjeder i viktige spørsmål og kommer i lojalitetskonflikter" (s. 20). Som ein konsekvens av dette blir studentane overlatne til sjølv å skape meiningsfulle samanhengar i utdanningsløpet sitt. 
Eit anna uttrykk for denne utfordringa kjem i form av korleis fagpersonar på utdanningsinstitusjonane ser sjølv: er dei først og fremst fagpersonar (t.d. fysiologar, sosiologar osv.) eller lærarutdannarar? Dette er ei utfordring i grunnskulelærarutdanninga (Lillejord \& Børte, 2014) som ikkje er noko mindre i kroppsøvingslærarutdanninga. Her hender det til dømes at studentane møter støttefag som fysiologi, anatomi eller sosiologi i fellesundervisning med andre idrettsvitskaplege utdanningar, og det er sannsynleg at slik undervisning ikkje nødvendigvis er skuleretta. På same måte kan vi spørje om øvingslærarane ser seg sjølve som lærarutdannarar? I vår undersøking kjem det fram at svaret på dette spørsmålet kan tolkast som både ja og nei. Nokre øvingslærarar arbeider først og fremst for å lære studentane opp i den praksisen dei sjølv er ein del av, andre øvingslærarar er opptekne av at det skal vere ein samanheng mellom det studentane lærer på høgskulane og det dei erfarer i praksisen.

Begge døma med kor vidt faglærarar og øvingslærarar ser på seg sjølv som lærarutdannarar gjer at kunnskapsobjektet kan bli uklart for studentane. Utfordringa er då korleis utdanninga og utdannarar kan sette studentane si lering $i$ sentrum?

\section{Utfordring 2: Medium for refleksjon}

Som nemnt har vi funne at skriving er ein viktig måte studentane arbeider med erfaringar frå praksis på (Standal \& Moe, 2011). Vidare har vi merka ein tendens til at studentane ikkje heilt ser hensikta med alle skrivearbeida dei må gjere (Standal, Moen \& Moe, 2013). Vi forstår det slik at skriving av refleksjonsnotat, loggar og liknande i ei vis mon blir erfart som uforpliktande pliktløp. Det er noko studentane må gjere, men som dei ikkje erfarer at har noko meining utover å oppfylle eit arbeidskrav. Andre, internasjonale studier viser til at studentar opplever å bli “journaled to death” (O'Connell \& Dyment, 2011, s. 234).

Skriving objektiverer erfaringar på ein måte som gjer erfaringane tilgjengelege for studenten sjølv og andre i ettertid. Slik sett kan refleksjonsnotat og loggar gjerast meir relevante gjennom tilbakemeldingar og framovermeldingar. Vidare kan skriftelege arbeid bli utnytta til å skape progresjon til neste praksisperiode og refleksjonsnotat (sjå Standal \& Rugseth, 2014). I tillegg er refleksjonsnotata potensielt sett et vindauge inn til det studentane blir opptatt av i praksisperioden og slik sett av stor verdi for dei som underviser studentane mellom praksisperiodar. Med andre ord kan refleksjonsnotat og loggbøker hjelpe undervisere til å skape integrasjon mellom de ulike kunnskapsformene studentane jobbar med ved å dra studentane sine praksiserfaringar meir medvite inn i undervisninga som føregår på universitet og høgskular.

Bølgja av digitalisering som høgare utdanning no er ein del av, opnar også opp for nye mogelegheiter til å ta vare på flyktige praksiserfaringar. Erfaring med bruk av videofilming av undervisning er positive og skapar mogelegheiter for å ikkje berre skrifteleggjere men også synleggjere saker studentane blir opptekne av i skulepraksisen $^{1}$. Vi ser også at bruk av digitale verktøy kan gjere at tida høgskulelærarane bruker på oppfølging av studentar kan bli meir effektiv. Praksisbesøka kan vere viktige for

\footnotetext{
${ }^{1}$ Sjå til dømes: www.uv.uio.no/proted/utviklingsomrader/digitale-leringsomgivelser/Videobasert \%20vurdering $\% 20$ for $\% 201 \%$ C3\%A6ring $\% 20$ av $\% 201 \%$ C3\%A6rerstudenter.
} 
høgskulelærarane sin kontakt med praksisfeltet og studentane sine erfaringar der, men bruk av videofilming og nettmøte kan gjere diskusjonar omkring studentane si læring meir konkret ved at ein kan forholde seg faktiske situasjonar og kople desse opp mot teori. Nettmøte kan vere ressurs- og tidssparande, og kan vere eit nyttig supplement til praksisbesøka. Utfordringa her blir då korleis ein kan bruke skriftelege arbeider og digital hjelpemiddel som video til å utvikle studentar sine profesjonskunnskapar?

\section{Teori / praksis-distinksjonen}

Både i tidlegare forsking og våre eigne prosjekt er forholdet mellom teori og praksis eit sentralt tema. Tidlegare forsking har påvist at studentar har eit skaprt og eindimensjonalt skilje mellom teori og praksis. Teori blir forstått som det å lese i bøker medan praksis er å utøve aktivitetar eller undervise om aktivitetar. (t.d. Larsson, 2009). Sjølv om vi har sett at dette er ein vanleg måte å omtale teori og praksis i samanheng med praksisopplæringa, så har vi samstundes fått fram eit meir nyansert bilete av kva studentane tenkjer på som teori og korleis dei ser teorien si rolle i skulepraksiskonteksten (t.d. Standal, Moen og Moe, 2013; Standal \& Rugseth, 2014).

Ludvigsen (2015, s. 221) minner om at "teori-praksis-distinksjonen fører ofte til at vi mister muligheten til å se på relasjonen mellom ulike kunnskapsformer, og hvordan disse er gjensidig konstituert $i$ handlinger og i selve grunnlaget for en profesjonell praksis". Dette er ei viktig presisering. Vi har i denne samanhengen hatt god nytte av Harald Grimen (2008) si forståing av praktiske syntesar. Grimen si tese er at profesjonskunnskap i stor grad er heterogen og fragmentert. Det vil seie at profesjonar vanlegvis hentar kunnskapane sine frå ulike vitskaplege disiplinar og kunnskapsfelt. Desse kunnskapsbasane vil som regel ha få eller ingen logiske samband, til dømes fordi dei bygger på ulike vitskaplege tradisjonar med forskjellige ontologiske og epistemologiske utgangspunkt. Sagt på ein annan måte: heterogenitet og fragmentering i kunnskapsbasen til ein profesjon er spørsmål om kvar elementa i kunnskapen er henta frå og kor sterkt eller svakt desse elementa heng saman.

Vidare skil Grimen mellom teoretiske og praktiske syntesar. Ein syntese er det som skapar samanheng og einskap i kunnskapen til profesjonen. Grimen skriv at "hvis det som integrerer elementene i en profesjons kunnskapsbase er de praktiske fordringer som profesjonens yrkesutøvelse stiller [heller enn en omfattende teori], har vi en praktisk syntese" (s. 72). Som hovudregel, seier Grimen, er det praktiske fordringar og ikkje ein omfattande teori som integrere kunnskapsbasen til profesjonar.

Ein konsekvens av at praktiske syntesar blir drivne fram av utfordringar studentane erfarer i yrkespraksis er at utsegner som "praksis er der eg verkeleg lærer kva det vil seie å undervise i kroppsøving” er eit grunnvilkår for det å vere lærarutdannar. Heller enn å sjå på det som eit uttrykk for at studentane er teori-fiendtlege, er det eit uttrykk for at studentane orienterer seg mot den yrkespraksisen dei seinare skal arbeide i. Utfordringa for praksisoppleringa blir då to-delt. På den eine sida at studentane utviklar ei nyansert og gjennomtenkt forståing av "de praktiske fordringane", altså innhaldet $i$ " $k v a$ det vil seie å vere larar" er. På den andre sida treng studentane deretter å få støtte, tid og 
rom til a utvikle meiningsfylte samanhengar mellom dei ulike kunnskapsformene som utfordrar deira idear og førestillingar om kva det å vere lerar består $i$.

\section{Avrunding}

I denne artikkelen har vi presentert ei oppsummering av fleire forskingsprosjekt vi har gjennomført om praksis i kroppsøvings- og idrettsutdanningar. Vi har gjort greie for sentrale funn og kort presentert teoretiske perspektiv vi har funne nyttige $\mathrm{i}$ arbeida våre. Særleg har vi lagt vekt på samspelet - partnarskapen - mellom høgskulelærarar, praksisrettleiarar (øvingslærarar) og studentar. Til slutt har vi røyst tre utfordringar for kroppsøvings- og idrettsutdanningar som har praksis. Desse utfordringane har vore knytt til kva som bør vere i sentrum for praksisen, korleis ein kan objektivere - i positiv meining - praksiserfaringar og korleis ulike kunnskapsformer kan spele saman i utdanninga. Som lærarutdannarar ser vi desse utfordringane som mogelegheiter og som inspirasjon for å vidareutvikle kroppsøvingslærarutdanninga og andre utdanningar innanfor det idrettsvitskaplege feltet som har praksis som ein vesentleg del.

\section{Biographies}

Øyvind Førland Standal var professor i idrettspedagogikk ved seksjon for kroppsøving og pedagogikk, Norges idrettshøgskole. No er han professor i kroppsøving ved fakultet for lærerutdanning og internasjonale studier, Høgskolen i Oslo og Akershus. Han er også professor II ved avdeling for folkehelsefag, Høgskolen i Innlandet. Øyvind underviser og forskar om kroppsleg læring og inkludering i kroppsøving.

Kjersti Mordal Moen er førsteamanuensis i kroppsøving ved seksjon for idrett og kroppsøving ved Høgskolen i Innlandet, avdeling for folkehelsefag. Kjersti underviser i profesjonsfaget på bachelorutdanningen i kroppsøving og idrettsfag, og forsker på kroppsøvingslærerutdanning og kroppsøving.

\section{Litteraturliste}

Backman, E., \& Larsson, L. (Eds.). (2013). I takt med tiden? Perspektiver på idrottslärarutbildning $i$ Skandinavien. Lund: Studentlitteratur AB.

Curtner-Smith, M. D. (2007). The impact of a critically oriented physical education teacher education course on preservice classroom teachers. Fournal of Teaching in Physical Education, 26, 35-56.

Curtner-Smith, M. D., \& Sofo, S. (2004). Influence of a critically oriented methods course and early field experience on preservice teachers' conceptions of teaching. Sport, Education and Society, 9(1), 115-142. doi: 10.1080/1357332042000175845

Dowling, F. (2011). 'Are PE teacher identities fit for postmodern schools or are they clinging to modernist notions of professionalism?' A case study of Norwegian PE teacher students' emerging professional identities. Sport, Education and Society, 16(2), 201-222. doi: 10.1080/13573322.2011.540425

Grimen, H. (2008). Profesjon og kunnskap. I A. Molander og L. I . Terum (red.), Profesjonsstudier (s. 71-86). Oslo: Universitetsforlaget.

Haug, P. (2013). Kva skal til for å endre lærarutdanninga? Bedre skole (3), 53-59.

Hegender, H. (2010). The Assessment of Student Teachersэ Academic and Professional Knowledge in School Based Teacher Education. Scandinavian fournal of Educational Research, 54(2), 151-171.

Larsson, L. (2009). Idrott - och helst lite mer idrott. Idrottslärarstudenters möte med utbildningen. University of Stockholm, Stockholm.

Lillejord, S., \& Børte, K. (2014). Partnerskap i lererutdanningen - en forskningskartlegging - KSU 3/2014. Retrieved from Oslo: Kunnskapssenter for utdanning, www.kunnskapssenter.no

Lortie, D. C. (1975). Schoolteacher: A sociological study: Chicago: University of Chicago Press.

Ludvigsen, S. (2015). Fagfornyelse, dybdelæring og progresjon i lærerutdanning. I U. Rindal, Lund, A., Jakhelln, R. (red.), Veier til fremragende lererutdanning (s. 221-228). Oslo: Universitetsforlaget. 


\section{Praksisopplering i kroppsøvingslerar- og idrettsutdanningar}

Lund, A., Jakhelln, R., \& Rindal, U. (2015). Fremragende lærerutdanning - hva er det, og hvordan kan vi få det? I U. Rindal, A. Lund, \& R. Jakhelln (red.), Veier til fremragende lererutdanning (s. 11-38). Oslo: Universitetsforlaget.

Maivorsdotter, N., Lundvall, S., \& Quennerstedt, M. (2014). Being a competent athlete or a competent teacher? Aesthetic experiences in physical education teacher education. European Physical Education Review, 20(3), 407-422. doi: 10.1177/1356336x14535058

Moen, K. M. (2011). "Shaking or stirring?": a case-study of physical education teacher education in Norway. (PhD), Norwegian School of Sport Sciences, Oslo.

Moen, K. M., \& Standal, Ø. F. (2014). Student teachers perceptions of the practicum in physical education teacher education in Norway. Nordic Studies in Education, (2), 111-125.

Moen, K. M., \& Standal, Ø. F. (2016). Practicum in Physical Education Teacher Education. An educational partnership? SAGE Open, 6(1), 2158244016635715.

Moen, K. M., Westlie, K., Brattli, V. H., Bjørke, L., \& Vaktskjold, A. (2015). Kroppsøving $i$ Elverumskolen. En kartleggingsstudie av elever, larere og skolelederes opplevelse av kroppsøvingsfaget i grunnskolen. Elverum: Høgskolen i Hedmark. Nedlasta frå: https://www.google.no/url?sa=t\&rct=j\&q=\&esrc=s\&source=web\& $\mathrm{cd}=1 \& \mathrm{cad}=$ rja\&uact $=8 \&$ ved $=0$ ahUKEwjUzbTi3dXTAhViDJoKHWz7AfMQFggnMAA\&url=https $\% 3 \mathrm{~A}$ $\% 2 \mathrm{~F} \% 2 \mathrm{Fbrage}$ bibsys.no\%2Fxmlui $\% 2$ Fhandle $\% 2 \mathrm{~F} 11250 \% 2 \mathrm{~F} 300725 \&$ usg=AFQjCNENXSR9OTeIWfz_ 0D9mVFA_MIP8rQ\&sig2=j2DNFR2N8UQIIQWaAO2QKg

Molander, A. \& Terum, L. I. (2008). Profesjonsstudier - en introduksjon. I: A. Molander \& L. I. Terum (red.), Profesjonsstudier (s. 13-28). Oslo: Universitetsforlaget.

Mordal-Moen, K., \& Green, K. (2014a). Neither shaking nor stirring: a case study of reflexivity in Norwegian physical education teacher education. Sport, Education and Society, 19(4), 415-434. doi: 10.1080/ 13573322.2012.670114

Mordal-Moen, K., \& Green, K. (2014b). Physical education teacher education in Norway: the perceptions of student teachers. Sport, Education and Society, 19(6), 806-823. doi: 10.1080/13573322.2012.719867

O'Connell, T., \& Dyment, J. (2011). Health and physical education pre-service teacher perceptions of journals as a reflective tool in experience-based learning. European Physical Education Review, 17(2), $135-151$.

Standal, Ø. F., Moen, K. M., \& Moe, V. F. (2014). Theory and practice in the context of practicum: The perspectives of Norwegian physical education student teachers. European Physical Education Review, 20(2), 165-178.

Standal, Ø. F., \& Moe, V. F. (2013). Reflective practice in physical education and physical education teacher education: A review of the literature since 1995. Quest, 65(2), 220-240.

Standal, Ø. F., \& Rugseth, G. (2014). Practicum in adapted physical activity: a dewey-inspired action research project. Adapted physical activity quarterly: $A P A Q, 31(3), 219-239$.

Standal, Ø. F., \& Rugseth, G. (2016). Experience, Intersubjectivity, and Reflection: A Human Science Perspective on Preparation of Future Professionals in Adaptive Physical Activity. Quest, 68(1), $29-42$.

Teige, E. (2016). Kritisk tenkning. I O. A. Kvamme, T. Kvernbekk, \& T. Strand (red.), Pedagogiske fenomener. En innføring (s. 106-117). Oslo: Cappelen Damm Akademisk.

Wackerhausen, S. (2008) Erfaringsrum, handlingsbåren kundskab og refleksion. Vol. 1: Institut for Filosofi \& Idehistorie.

Winch, C., Oancea, A., \& Orchard, J. (2015). The contribution of educational research to teachers' professional learning: philosophical understandings. Oxford Review of Education, 41(2), 202-216. doi: $10.1080 / 03054985.2015 .1017406$ 